\title{
State, Society and Gender Disparities in Bangladesh, India and Pakistan
}

\author{
Dr. Shalini Gupta \\ (Assistant Professor, Department of Economics, School of Social Sciences, Doon University, Dehradun, \\ Uttarakhand, 248001, India)
}

\begin{abstract}
Bangladesh, India and Pakistan, which once were parts of one country, reflect huge variations in gender disparities. These gender disparities are the result of social, cultural, economic, political and institutional factors in these countries. This paper analyses gender disparities in Bangladesh, India and Pakistan, focusing on the state and society. Social norms and practices along with constitutional provisions and legal framework have been examined in these countries in the context of gender gaps. Certain key parameters, reflecting the state of women in these countries have also been examined. It is noted that Bangladesh, which is the youngest and the poorest country among the three, has made fast strides in reducing gender disparities leaving India and Pakistan far behind. There is no evidence of reduction in gender disparities in Pakistan, the country from which Bangladesh broke away to become an independent country. Rather gender disparities have become more pronounced over time in Pakistan. India has also not made any significant progress in reduction of gender disparities. The study concludes with policy implications.
\end{abstract}

Keywords: Domestic violence, Education, Gender disparities, Health, Sex-ratio, Work participation rate

\section{Introduction}

Bangladesh, India and Pakistan were parts of the Indian subcontinent until 1947. Bangladesh and Pakistan have predominantly Muslim population. India is a secular country but is a home to one of the largest Muslim population in the world. Secularism is woven into the fabric of the Indian constitution via an amendment to the preamble of the Constitution in 1976. This means a policy of non-interference in the 'personal laws' of the religious communities of the country [1]. The Directive Principles of the State Policy in the constitution of India call for the institution of a uniform civil code (a uniform operation of personal laws) in the country. However, in the name of 'minority-appeasement', the issue of discrimination against women in the personal laws has remained an extremely sensitive issue in the politics of India and no political party is willing to touch upon this issue. The history of secularism in Pakistan has been a chequered one. Islamic ideology was formally incorporated into the Constitution in the early 1950s. But under martial law in 1962, the word 'Islam' was dropped. However, it was re-incorporated in the constitution in 1973. Pakistan is now officially declared to be an Islamic Republic, though different personal laws are practiced for different communities in the country. Secularism was incorporated in the constitution of Bangladesh at the time of its inception. However, secularism was replaced by 'absolute trust and faith in almighty Allah' in 1988. Islam was made the state religion of Bangladesh under the rule of General Ershad. Gender disparities must be addressed with this background.

There are stark differences in the gender gaps in Bangladesh, India and Pakistan as per the Global Gender Gap Report 2013 released by the World Economic Forum. The report ranks Bangladesh, India and Pakistan at 75, 101 and 135 respectively among 136 countries. The report ranks the countries by measuring the size of the gender inequality gap in four areas namely, economic participation and opportunity, health and survival, educational attainment and political empowerment. The questions are: whether these differences can be attributed to the prevailing norms and practices in the society of these countries or to their constitutional or legal framework; whether the state and legal responses to the rights of women significantly differ in Islamic countries as opposed to a secular country. An attempt has been made in this paper to understand the influence of traditional social norms and practices along with the legal and constitutional framework on marginalisation of women in these three countries.

The study contains five sections. The introduction is followed by the second section, which examines the social and cultural context of societies in Bangladesh, India and Pakistan. The third section considers the legal and constitutional framework existing in these countries for ensuring gender equality. The fourth section highlights the key parameters reflecting the gender disparities in these countries and finally, the fifth section concludes with brief outlook on policy implications. 


\section{The social and cultural context of societies}

Bangladesh is one of the few democracies in the Muslim world. The Bengalis form the country's predominant ethnic group. The four main religions in the country are Islam (89\%), Hinduism (9\%), Buddhism (1\%) and Christianity (0.5\%) [2]. The rural society in Bangladesh has a high degree of linguistic, religious and ethnic homogeneity, unlike the other countries of South Asia. This makes it easier to organize women and it significantly contributes to the success of development campaigns. Government programs are, therefore, easier to design and deliver [3].

India is the largest functioning democracy in the world. Out of the total population of India in the year 2001, 80.5 per cent were Hindus while Muslims accounted for 13.4 percent and Christians 2.3 percent respectively [2]. India is a multi-cultural, multi-lingual and multi-ethnic society. There is no single culture, which can be called Indian culture as each regional, linguistic, religious and caste group has its own culture. The social and cultural patterns of India exhibits pluralism in terms of language, geography, ethnicity, religion and culture. However, subordination of women is relatively more in Northern India where the impact of the patriarchal structure is more pronounced in the family life [4].

In Pakistan, Muslims account for 96.4 percent population, while others (including Christians and Hindus) are 3.6 percent [2]. Pakistan has four provinces namely, Punjab, Sindh, Khyber Pakhtunwa and Baluchistan, which have been structured around four main ethnic groups: the Punjabis, Sindhis, Pashtuns and Baluchis. Each of these ethnic groups is characterised by a variety of sub-groups based on ethno-linguistic, occupational and caste divisions. The social and cultural context of Pakistani society is predominantly patriarchal [5]. Women have a low percentage of participation in society outside of the family [6]. Women in Pakistan are subjected to oppression and brutality in a male dominated society. Violence committed against women at home is generally swept under the carpet, which includes physical, verbal, sexual (marital rape) and psychological abuse [1]. In many ways, Pakistan's people lack substantive citizenship. Citizens, particularly the poor and women, lack the formal means to make their voices heard and to influence or hold their leaders and service providers to account [7].

Patrilineal ties dominate the ideology of family life in Bangladesh, but in practice matrilineal ties are equally important [8]. In Bangladesh society strongly discourages polygamy and it is rarely practiced among Muslims [9]. This is not the case in India and Pakistan. India and Pakistan are caste ridden societies where each caste group has its own characteristic features. Gender inequality has been embedded within society in India and Pakistan. Traditional patriarchal norms in these countries have relegated women to secondary status within the household. Girls are often seen as a burden that parents can ill afford, largely due to the hefty dowry that is required to marry them off. Moreover, the deeply entrenched social hierarchies based on class, caste, ethnic and communal divisions leave women in many communities on the margins with little knowledge of their rights and even less protection from local, state and national governmental policies.

\section{The legal and constitutional framework for ensuring gender equality}

One of the major legacies of colonial rule in the Indian subcontinent was categorisation of the personal laws as purely religious laws. This created problems in implementing gender equality. In principle, gender equality is safeguarded by the constitutions of Bangladesh, India and Pakistan and the constitutional frameworks extend affirmative action to bring women and other vulnerable groups into the mainstream of national life. Yet this formalized equality in all the three constitutions is undermined by the plurality of legal systems and customary practices that exist in reality. The spirit of these societies and the ground realities prevailing are discussed further.

After its formation, Bangladesh moved steadily forward to legally guarantee equal rights for women and to protect women from discrimination and violence. It became a party to a series of international conventions to promote gender equality and reduce violence against women. Significant reforms in respect of Muslim Family Laws, particularly in case of polygamy, divorce etc., were undertaken in Bangladesh to protect women's interest. This signifies that given the will and the intent, the Sharia Law is not immutable in a country where Islam is the state religion [6]. The government of Bangladesh is receptive to reforms in laws and endorses the need for such measures to ensure the well-being of its people and society. The Domestic Violence (Protection and Prevention) Act adopted in 2010 is another important law in this direction that criminalizes domestic violence in Bangladesh.

India has always actively participated in international conventions for promotion of gender equality. India has ratified various international conventions and human rights forums to secure equal rights for women. India is one of the first countries to enact legislation to create opportunities for political participation of women at the grassroots. India has a plethora of laws to protect women's rights. These include banning child marriage, pre-natal sex determination tests, domestic violence and dowry. But these laws are seldom enforced. Ironically, a few laws promoting gender inequality co-exist with gender sensitive laws in India. For example, law excluding daughters and widows from inheriting land still exist in India. Similarly, there is the Goa polygamy 
law which actually permits a second marriage for the husband, when there is no son from the first marriage [10]. These laws have lowered the status of Indian females and such legislation needs to be repealed. Besides this, there is a need to strictly implement gender sensitive laws. However, lack of political will is responsible for nonenforcement of gender laws in India.

Pakistan has signed a few international conventions for promotion of gender equality. However, Pakistan signed the Convention on the Elimination of all Forms of Discrimination against Women (CEDAW), an international treaty, which is described as an international bill for the rights of women, with some reservations [11]. There is a parallel system of Sharia courts in Pakistan [12]. In 1979, Zia ul-Haq's Government introduced the Hudood Ordinance for the first time in Pakistan, which prescribed Shariabased punishments for the use of liquor, theft and adultery [7]. Some interpretations of Sharia are used to justify cruel punishments such as amputation and stoning, and unequal treatment of women in inheritance, dress and independence [13]. There is no law in Pakistan for prevention of domestic violence. In addition to existence of formal legal systems and Sharia courts in Pakistan, there also exist parallel systems, which are informal and illegal. The traditional and informal systems of decision making present in the rural communities across Pakistan completely exclude women. Decision-making forums such as Jirga and panchayat are essentially councils of tribal elders or 'chiefs'. The council deliberates and rules on all matters affecting the community. Its decisions are usually binding with imposition of severe sanctions for ignoring its rulings [14]. The jirgas and panchayats in certain districts have indeed issued statements forbidding women to vote. Although this has been brought to the notice of the Election Commission, yet no corrective measures have been taken. In Pakhtun society of Pakistan, the women do not have access to the hujra (where men discuss matters and socialise).

\section{Key parameters reflecting the gender disparities}

This section reflects some of the key indices that indicate the gender disparities prevailing in the three countries under consideration.

4.1 Fertility Rates: Trends of fertility rates shown in Table 1 and Fig.1 indicate that Bangladesh has been the most successful in reducing fertility rates among the three countries. In the year 2004 fertility rate was 2.7 in Bangladesh which came down to 2.2 in 2011, whereas the corresponding figures for India were 2.9 and 2.5 respectively. Fertility rates are very high in Pakistan. In Bangladesh, the acceptance of small family norm is practiced by all. Freedom from frequent child bearing and resultant depletion of energy has improved women's health in Bangladesh.

Table 1: Fertility rate data

\begin{tabular}{ccc}
\hline & $\mathbf{2 0 0 4}$ & $\mathbf{2 0 1 1}$ \\
\hline Bangladesh & 2.7 & 2.2 \\
India & 2.9 & 2.5 \\
Pakistan & 3.9 & 3.3 \\
\hline
\end{tabular}

Source: World Bank Database

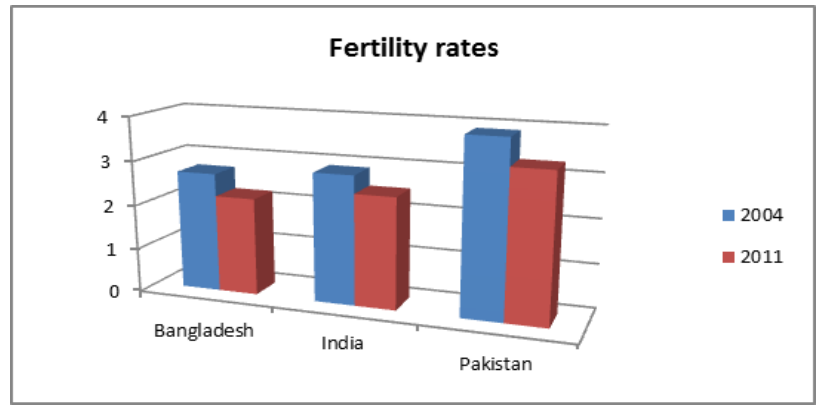

Figure 1: Fall in fertility rates (total births per woman)

4.2 Life expectancy at birth: It is interesting to note from Table 2 and Fig. 2 that life expectancy at birth for females is the highest in Bangladesh followed by India and Pakistan. Life expectancy at birth for females was 70.7, 67.7 and 67.2 respectively in Bangladesh, India and Pakistan in the year 2011. This is a direct indicator of better health of women in Bangladesh, which can partly be explained in terms of decline in fertility rate.

Table 2: Life expectancy data

\begin{tabular}{cc}
\hline & $\mathbf{2 0 1 1}$ \\
\hline Bangladesh & 70.7 \\
India & 67.7 \\
Pakistan & 67.2 \\
\hline
\end{tabular}

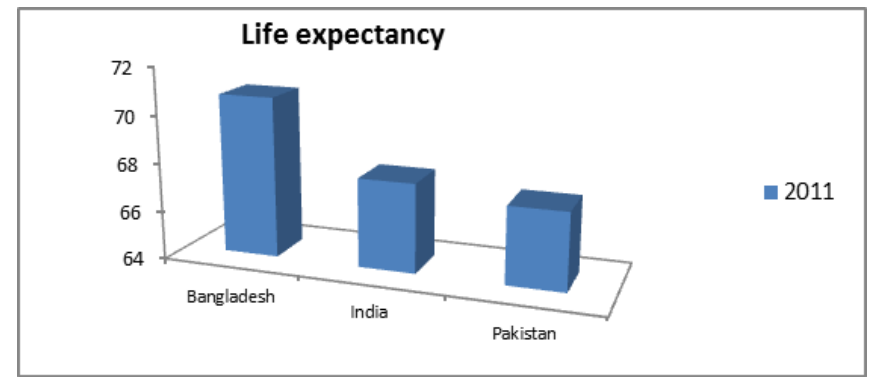

Figure 2: Life expectancy at birth, female (years) in the three countries 
4.3 Female to male infant mortality rate: Trends in female to male ratio of infant mortality rates (per 1,000 live births) shown in Table 3 and Fig. 3 indicate that only Bangladesh has been successful in reducing female infant mortality rates among the three countries. In the year 2010 female to male ratio of infant mortality rates was 0.9 in Bangladesh which came down to 0.8 in 2012, the corresponding figures for Pakistan were 0.9 in both the years. In case of India female to male ratio of infant mortality rates has increased drastically in short span of two years from 2010 to 2012 as the figure shot up from 0.7 to 1.0. This reflects increasing apathy and negligence of female infants in India. In most parts of India, a preference for male child is built into the cultural ideology. Sons are traditionally viewed as the breadwinners who will carry on the family name and perform the last rites of the parents, an important ritual in many faiths.

Table 3: Ratio of female to male infant mortality rate

\begin{tabular}{ccc}
\hline & $\mathbf{2 0 1 0}$ & $\mathbf{2 0 1 2}$ \\
\hline Bangladesh & 0.9 & 0.8 \\
India & 0.7 & 1.0 \\
Pakistan & 0.9 & 0.9 \\
\hline
\end{tabular}

Source: World Bank Database

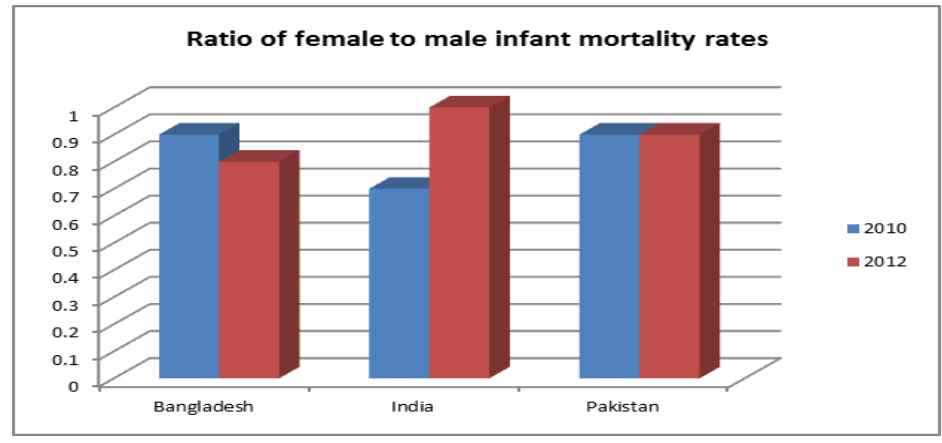

Figure 3: Ratio of female to male infant mortality rate

4.4 Ratio of girls to boys in education: Ratio of girls to boys in primary and secondary education in the year 2011 and shown in Table 4 and Fig. 4 do indicate that Bangladesh has attained far greater success in educating their girl child as compared to India and Pakistan. This has also contributed to reduction of gender disparities in Bangladesh.

Table 4: Ratio of girls to boys in primary and secondary education $(\%)$

\begin{tabular}{cc}
\hline & $\mathbf{2 0 1 1}$ \\
\hline Bangladesh & 109.6 \\
India & 98.4 \\
Pakistan & 81.7 \\
\hline
\end{tabular}

Source: World Bank Database

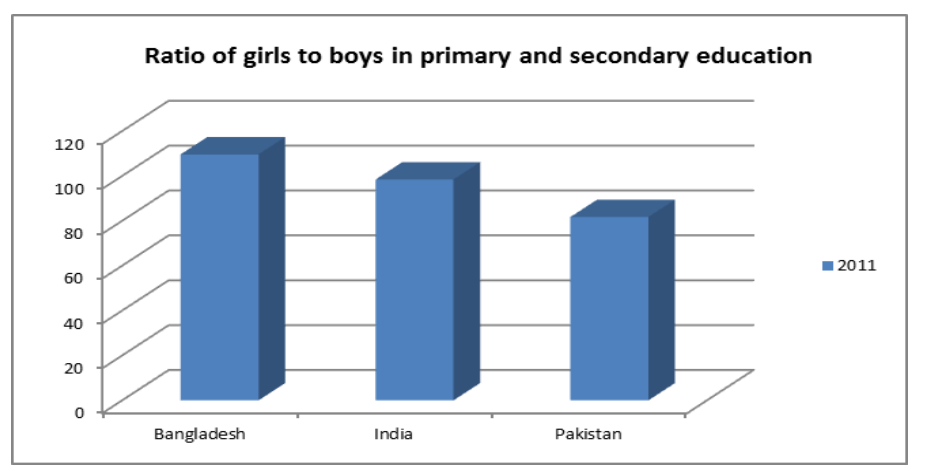

Figure 4: Ratio of girls to boys in primary and secondary education (\%)

4.5 Female to male labour force participation: Ratio of female to male labour force participation rates as shown in Table 5 and Fig.5 indicate that Bangladesh is providing significantly higher job opportunities to women. The figure is almost double that of the Indian figure. Therefore, there is an economic reason behind reduced gender disparities in Bangladesh. India and Pakistan, on the other hand, have very few jobs for women. In case of India, the ratio of female to male labour force participation rate has actually declined significantly from 43.6 in 2004 to 35.6 in 2012. This shows that employment market is biased against women in India. This can partly explain higher gender inequality in India.

Table 5: Ratio of female to male labour force participation rate $(\%)$

\begin{tabular}{ccc}
\hline & $\mathbf{2 0 0 4}$ & $\mathbf{2 0 1 2}$ \\
\hline Bangladesh & 64.8 & 68.1 \\
India & 43.6 & 35.6 \\
Pakistan & 21.4 & 29.4 \\
\hline
\end{tabular}

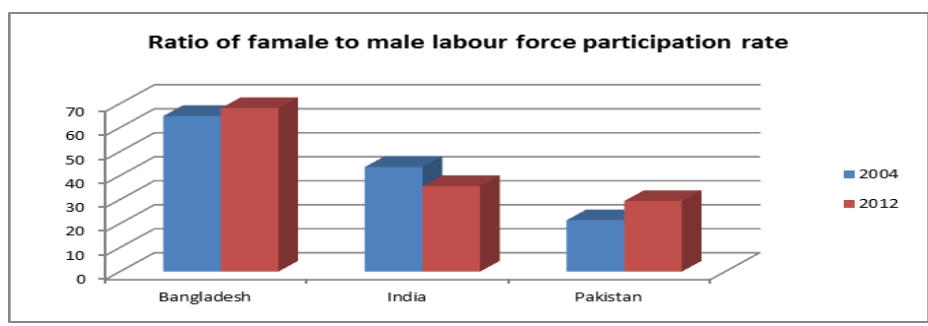

Figure 5: Ratio of female to male labour force participation rate (\%) 
4.6 Sex ratio at birth: Sex ratio at birth, defined by the ratio of number of males to females, is tilted in favour of males in all the three countries. However, it is evident from Table 6 and Fig.6 that the sex ratio at birth is highly skewed for India. This imbalance in sex ratio at birth reflects a strong preference for son in the Indian society. This imbalance is a result of the practice of gender biased sex selection, a manifestation of deep seated patriarchal mind-sets leading to the preference for sons over daughters; aided by technological misuse. A 2011 study conducted by the British medical journal (Lancet) in 2011 found that twelve million Indian girls have been aborted in the last three decades [15]. Some of the consequences of an imbalanced child sex ratio are an increase in violence against women and girls, trafficking for marriage and restrictions on mobility and choices of young girls.

Table 6: Sex- Ratio at birth

\begin{tabular}{cc}
\hline & $\mathbf{2 0 1 3}$ \\
\hline Bangladesh & 1.04 \\
India & 1.12 \\
Pakistan & 1.05 \\
\hline
\end{tabular}

Source: CIA World Fact Book

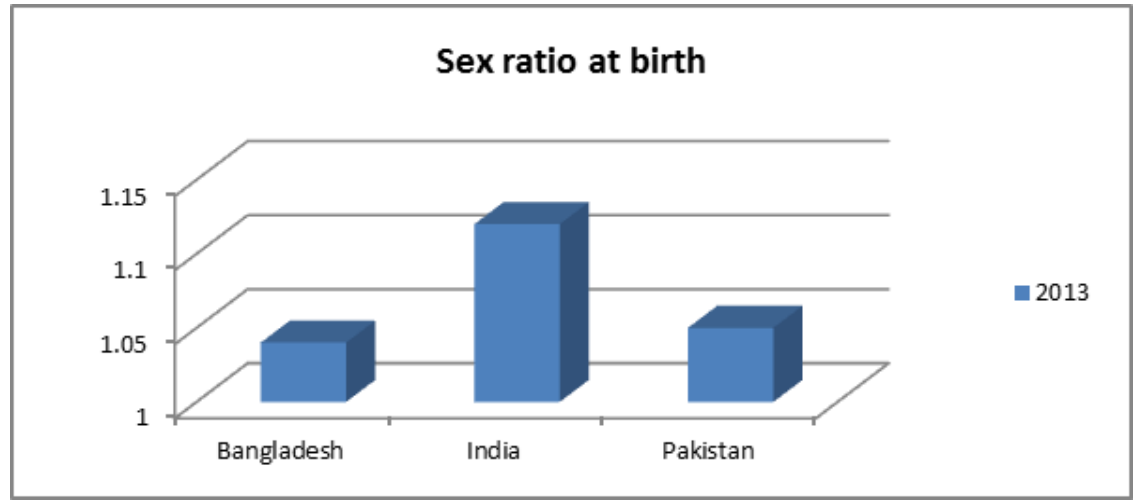

Figure 6: Sex-Ratio at birth (no. of males / no. of females)

4.7 Percentage population with access to improved sanitation: Bangladesh, India and Pakistan are still largely rural countries as they had 71.6, 68.7 and 63.8 per cent of their population living in the rural areas in 2011 respectively [2]. Data on access of population to improved sanitation facilities in rural areas reflects that Bangladesh is way ahead of India and Pakistan. This has resulted in improved health of its rural population and saved women from the drudgery of taking care of the family members. These are shown in Table 7 and Fig. 7.

Table 7: Population with access to improved sanitation facilities in $2011(\%)$

\begin{tabular}{ccc}
\hline & Urban & Rural \\
\hline Bangladesh & 55.3 & 54.5 \\
India & 59.7 & 23.9 \\
Pakistan & 71.8 & 33.6 \\
\hline Source: CIA & World Fact Book
\end{tabular}

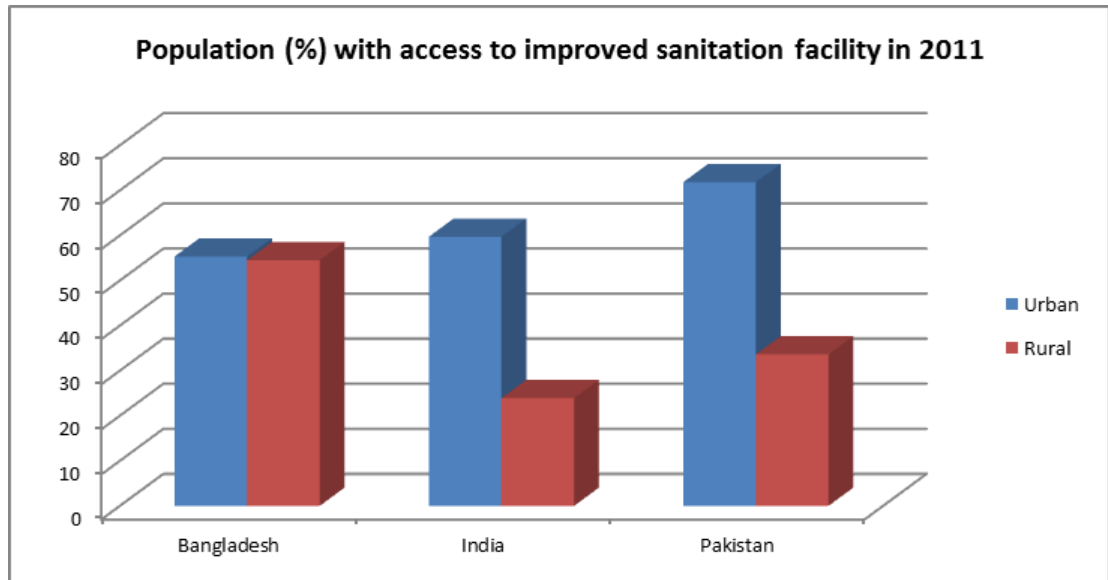

Figure 7: Population (\%) with access to improved sanitation facility in 2011

A brief look at the above data indicates that Bangladesh has outperformed the other two countries on all parameters related to education, work participation and health. This has resulted in reduction of gender disparities and empowerment of women in Bangladesh. However, to understand the Bangladesh phenomenon, it would be worthwhile to examine some of the changes the country witnessed during the past few decades. NGOdriven microcredit program and the government's education policy have been major drivers for reducing gender disparities in Bangladesh [16]. The focus on primary schooling in the 1980s and the 'Female Secondary School Stipend Program' in the 1990s led to significant improvements in educational attainment of females. The Malthusian hype about overpopulation in Bangladesh in the early 1970s led to an aggressive supply-driven family planning program that provided door-step delivery of contraceptives to women who had traditionally been in purdah [3]. This resulted in a dramatic decline in fertility rate. The freedom from childbearing improved women's health, the health of their children and also enabled them to engage in other activities. Similarly in the 'total sanitation drive', the focus was on behavioural change to move away from open defecation to use of 
toilets. Though the campaigns for clean drinking water, the campaign against childhood diarrhoea and the immunization campaign were not intended to be programmes to reduce gender inequality, yet each of these programmes empowered women indirectly. The toilets in schools enabled girls to go to secondary schools, reduction of diarrhoea promoted child health and reduced mothers' drudgery. Finally, the 'Multi-Fibre Trade Agreement', that gave Bangladesh concessions in garment trade, enabled the establishment of large export oriented garment factories. Since sewing has been a skill that women and girls traditionally learn in Bangladesh, these factories employed young women who had some education, who were unmarried and who provided cheap labour. In the process, a whole new generation of young women broke the shackles of familial and societal control and migrated out of their villages to develop their own identity. However, the scenario in Pakistan and India is very different.

Islamist extremists have gained significant ground in Pakistan in the recent years and talibanisation of the society in Pakistan has further worsened the already dismal state of women. Violence against women is high in Pakistan and is compounded by the inertia of the government to act. Successive governments in Pakistan have paid only lip service to the cause of women and gender mainstreaming. No government has shown the courage to grapple with the primitive gender discriminatory practices inherent in the political, social, legal and cultural systems of Pakistan. There has been a continuation of oppressive policies against women in the society.

India's international image is commonly tied to its economic performance as one of the emerging BRIC economies. However, this optimism is clouded by the findings of a poll conducted by Thomson Reuters in 2011, according to which India is the fourth most dangerous country in the world for women [17]. Women's empowerment in India still has a long way to go.

\section{Conclusions}

In Indian sub-continent women face discrimination and are subjected to violence and economic exploitation. Deep rooted patriarchy, religious practices, discriminatory laws against women and children, denial of property rights to women and so forth contribute to the creation of an environment which results in their systematic subordination. In poor families, both boys and girls help with household chores from a very early age, but as they grow older, the burden on girls increases disproportionately. By the time they reach adolescence, girls carry a major share of the burden of survival tasks including fetching water, collecting wood for fuel and fodder, cooking, cleaning and caring for younger siblings. So even though education might not financially burden the family, it does cost them the time she spends at school when she could be doing household chores. In addition, even though a woman is educated, especially in the poorer regions, there is no hope of her getting a job. Most jobs women perform are agricultural or domestic and these do not require a formal education. A vast majority of women work throughout their lives. The paradox is that this fact is not officially recognised as it is mostly outside the economic ambit. Statistics on work-force participation rates continue to show low figures for women workers. Women are viewed as an economic liability despite their contribution in several ways to our society and economy.

The social environment, which ensures a safe pregnancy, care and rest, reduced workloads and adequate nutrition are beyond the reach of many women. Most women do not have the luxury of maternity leaves. Women who are dependent on a daily wage often work in the fields until the labour moments and go back to work as soon as possible after the birth.

The crime graph against women is increasing at an alarming rate. Domestic violence, rape, sexual exploitation, molestation, eve-teasing, forced prostitution and sexual harassment at work places etc. are common today. The threat of violence curtails freedom of women. In addition to outside violence, rampant domestic violence also subjugates women. There is increasing evidence to show that all women, regardless of age, class, caste and community are vulnerable to domestic violence. Violence against women within families is often justified and condoned as being necessary to establish men's authority over women, to discipline them and to punish them for dereliction of duty. This view is held not only by men, but often by elderly women themselves. Once again, education appears to be a significant parameter in determining women's levels of tolerance towards violence. There is a strong need to firmly implement the laws to protect women. Also, new laws are required to criminalise marital rape and so-called "honour killings".

Of course, all women are not equal. Women belonging to the privileged and dominant classes and castes enjoy freedom and opportunities that are denied even to men from subordinate and underprivileged groups. Yet, women are at the bottom of the pile in every one of these groups. The poorest and most powerless individual is actually a woman.

A nation's progress and prosperity can be judged by the way it treats its women folk. There are many things that need to be done to ensure gender equality. Better implementation of legal provisions and strengthened access to justice is the need of hour. The gap in policy and practice in women's empowerment is most visible when it comes to the level and kinds of violence women face in the Indian subcontinent. Besides this, the process of economic growth must be linked to an expansion in opportunities for women. Women's 
access to basic social services must be increased. Awareness, access, availability and affordability of education, nutrition and health services should be ensured. As a welfare state, the government has the responsibility of ensuring resource allocation for the development of the entire population, including women. Yet, in contrast to development plans for other sections of the population, government emphasis with respect to women is not on redefining development through resource allocation. It is largely restricted to awareness raising and mobilisation. Moreover, in the present era of economic liberalisation, privatisation and globalisation, the governments are gradually moving away from being direct provider of services to being facilitators. They are curtailing expenditure on social sector. There are debates at the global level on whether the government should cut unproductive spending on social sector (education, health, potable drinking water, improved sanitation and so forth) or transfer them to the private sector, which can provide these services more efficiently and cheaply. Even small improvements in these areas can make significant difference to the condition of women. Reduced spending on these sectors can cause irreversible damage to women. The issues to ponder, therefore, are: How to protect the interests of women and other marginalised groups, if these sectors are handed over to the private sector whose sole motto is profit maximization rather than considerations of social justice and equality? Similarly, planners must answer the hard questions on the nature of economic growth, that is, whether growth is inclusive of women? Is growth creating jobs for women? Is it protecting the interests of women?

It is recognized that massive social change is required for reducing gender gaps and social change is a slow process. Can we say that Bangladesh is a model? The answer may be 'No'. However, Bangladesh has indeed offered lessons and has shown a way to move forward.

\section{Acknowledgements}

The author is thankful to Prof. V. K. Jain, Vice-Chancellor, Doon University for his constant motivation to carry out this study.

\section{References}

[1] http://www.unwomensouthasia.org/assets/complete-study.pdf (Retrieved on 07-02-2014)

[2] https://www.cia.gov/library/publications/the-world-factbook/ (Retrieved on 07-02-2014)

[3] World Bank Report funded by AusAID. (2007) WHISPERS TO VOICES Gender and Social transformation in Bangladesh. http://siteresources.worldbank.org/ INTBANGLADESH/Resources/ (Retrieved on 7- 02-2014)

[4] Jejeebhoy, S. J. (1998) Wife-Beating in Rural India: A Husband's Right? Evidence from Survey Data. Economic and Political Weekly, 33(15), 855-862

[5] Bari, F. and Pal, M. S. (2000) Women in Pakistan: Country briefing paper. Programs Department (West) and Office of Environment and Social Development. Asian Development Bank.

[6] Asia's women in agriculture, environment and rural production: Pakistan. http://www.fao.org (Retrieved on 07-02-2014)

[7] Mezzera, M. Aftab, S. (2009), Pakistan State-Society Analysis. The Initiative for Peacebuilding, Neitherland's Institute of International Relations. http://www.clingendael.nl/sites/default/files/20090300_cru_pakistan_mezzera.pdf (Retrieved on 07-022014)

[8] http://en.wikipedia.org/wiki/Bangladeshi_society (Retrieved on 07-02-2014)

[9] http://bangladeshcorruption.wordpress.com/tag/hindus/ (Retrieved on 07-02-2014)

[10] UNFPA (2013) "The Law and Son Preference in India: A Reality Check" - a study of the U.N. World Population Fund

[11]http://www.humanrightsimpact.org/fileadmin/hria_resources/HeRWAI_Centre/summaries/Summary_Raana_Zahid_WGNRR_opbouw. pdf (Retrieved on 07-02-2014)

[12] http://www.crisisgroup.org/ /media/Files/asia (Retrieved on 07-02-2014)

[13] http://www.cfr.org/religion/islam-governing-under-sharia/p8034 (Retrieved on 07-02-2014)

[14] National Commission on Status of Women (NCSW) (2011) A Study of Formal and Parallel Legal Systems Prevalent in Pakistan.

[15] http://in.reuters.com/article/2013/11/14/india-girls-laws-idINDEE9AD0B120131114 (Retrieved on 07-02-2014)

[16] Anand, V. (2014) Microfinance: State-of-the-art paradigm for women's empowerment in Bihar. IOSR Journal of Humanities and Social Science, 19(1), 05-08

[17] http://in.reuters.com/article/2011/06/15/idINIndia-57703820110615 (Retrieved on 07-02-2014) 